\title{
Influencia organizacional en el desarrollo turístico del cantón Guamote, Ecuador
}

\section{Organizational influence on tourism development in Guamote, Ecuador}

\author{
Gabriela Elizabeth Proaño Lucero ${ }^{1}$.
}

\begin{abstract}
.
The main objective of the present work was to determine the influence of the local municipal tourist organization on the tourist development of the Guamote canton, province of Chimborazo. Offering reliable and updated information to achieve an adequate management of the territory, and to be able to generate multiple benefits to the local inhabitants, framed in the objectives and guidelines that the governmental institution has to achieve the integral tourism development. Specifically, within the Tourism Unit and thus contribute to strengthening local tourism development, based on the situational analysis, detecting shortcomings, considering the entity as a public enterprise aimed at improving the provision of services to enhance tourism in the canton. For the information survey, two populations were considered, the service providers and the economically active population, in order to know the existing reality in the territory for decision making that would satisfy the needs of the sector with viable proposals that would further increase the institutional image of the municipality. The work involved statistical processes carried out in the SPSS software, version 25; such as the cronbach alpha that determined the reliability of the instruments, the analysis and interpretation of the results; and finally the testing of the hypothesis with chisquare determining in this way the existing dependence between the organization and the tourist development.
\end{abstract}

Keywords: Organization, Tourism development, Management model, Local tourism

\footnotetext{
${ }^{1}$ Escuela Superior Politécnica de Chimborazo - Sede Orellana, Licenciatura en Turismo, Ecuador, gabriela.proano@espoch.edu.ec
} 


\section{Resumen.}

El objetivo principal del presente trabajo fue determinar la influencia de la organización local turística municipal en el desarrollo turístico del cantón Guamote, provincia de Chimborazo. Brindando información correcta y actual y así obtener una gestión de calidad en el territorio, y generar muchos elementos positivos en la población local, según los objetivos y normas que posee la institución pública para un progreso del turismo en toda su dimensión. Particularmente en la Unidad de Turismo, desde un análisis de la localidad, revelando deficiencias, teniendo en cuenta a la institución como una entidad pública siempre en la disposición de tener mejores servicios en para fortalecer de manera integral el turismo del Cantón. Para obtener la muestra de estudio se tuvo en cuenta dos poblaciones, los prestadores de servicio y la población económicamente activa, con el fin de conocer la realidad existente en el territorio para la toma decisiones que satisfagan las necesidades del sector con propuestas viables que permitan aún más aumentar la imagen institucional del municipio. Para ello se aplicaron procesos estadísticos realizados en el software SPSS, versión 25; como el alfa de Cronbach que determinó la confiabilidad de los instrumentos, el análisis e interpretación de los resultados; y finalmente la comprobación de la hipótesis con chi-cuadrado determinando de esta forma la dependencia existente entre la organización y el desarrollo turístico.

Palabras clave: Organización, Desarrollo turístico, Modelo de gestión, Turismo local.

\section{Introducción.}

El turismo es muy importante en los procesos de desarrollo económico y social de los pueblos; además interviene en la toma de decisiones dentro de las direcciones territoriales, en la prestación de servicios atender a las insuficiencias y peticiones, y beneficiando el progreso socio-económico, al ser representantes reflexivos de las oportunidades que tiene la zona, pero también del compromiso para poder certificar la sostenibilidad del destino.

Hoy el Ministerio de Turismo (2018) plantea que el Ecuador despunta por primera vez los dos millones de turistas extranjeros entre enero y octubre del 2018, poniendo de manifiesto un aumento del 56\% con la misma etapa de 2017. En estas circunstancias es preciso tener en cuenta que el turismo ha crecido, a través de las políticas gubernamentales para posesionar al nuestro país como destino turístico de calidad; y a las destrezas de nuestro gobierno para inclinar al turismo como una de las principales fuentes de ingresos económicos y ser dependientes del petróleo.

Los Gobiernos Autónomos Descentralizados Municipales tienen que practicar las aptitudes trasladadas desde el Ministerio de Turismo, siendo imprescindible que haya una generación de que se genere cumplimiento entre los establecimientos públicas y la 
práctica, teniendo presente los elementos ambientales, las poblaciones y viajeros presentes en la región en constante interacción para el fomento del impulso del turismo.

Esta situación se antepone en algunas empresas pues hay déficit de liderazgo e inexistencia de manejos correcto en el área turística, producto de insuficientes programas de impulso de las dependencias que tienen que estimular el turismo, o por problemas en la administración que complejiza su puesta en marcha. Al examinar los datos obtenidos del Gobierno Autónomo Descentralizado del Cantón Guamote, (2014-2019), en el campo el $81,62 \%$ de la población está vinculada al sector primario agropecuario, el 4,60\% al sector secundario, el 6,24\% al sector terciario, el 6,61\% corresponde a las actividades que no se declaran y el $0,93 \%$ figura a los nuevos empleados, por consiguiente, solamente el $6 \%$ emplea o ejecuta acciones turísticas.

El elemento esencial es la componente turístico del Gobierno Autónomo Descentralizado del Cantón Guamote, donde hay un insuficiente proceso organizacional y no existe manual de funciones por el que se pueda aplicar las competencias y así ejercer correctamente el inventario de control de los locales de estancia y alimentación, inscripción de los turistas, y esto se le puede agregar la falta de cuidado de los atractivos de la naturaleza y la cultura, y la falta de apoyo de las entidades públicas y privadas. Las acciones de fomento y declaración son por parte de centros turísticos privados, junto a los datos efectivos del cantón; todo producido por la fortuita ayuda tecnológica y el erróneo fortalecimiento del gobierno municipal, que es a quien le conveniente a proyectar el progreso del cantón.

Además, al no haber una correcta programación, la falta de conocimiento y el no empoderamiento de las personas provoca que el destino Guamote no sea muy conocido para el turismo y que, de esta manera, se pueda trasformar esta acción en un elemento esencial y desarrollador de la economía, mejorando de manera directa a las comunidades que intentan mejorar su economía.

Nuestro estudio trata sobre mejorar la gestión del grupo directivo de turismo del cantón Guamote, y así contribuir al progreso turístico de éste, sobre la base de elementos que den a la región la posibilidad de una gestión correcta n el área del turismo.

Partiendo de estos antecedentes, nuestra investigación intenta fortalecer los procesos directivos del departamento de turismo del Gobierno Autónomo Descentralizado del Cantón Guamote con un análisis estos importantes procesos y así coadyuvar a estrategias realmente mejores y reales que fortalezcan la entidad.

El turismo es un movimiento muy activo que favorece un proceso educativo de nivel y a la igualdad de género, ya que, al arrancar con la aplicación de los lineamientos estratégicos para el crecimiento del turismo, se incluiría a todos, logrando un trabajo unido en el mejoramiento de la calidad de vida. 
Con este estudio se desea favorecer a cinco de los diecisiete objetivos de desarrollo sostenible propuesto por la Organización de las Naciones Unidas (2016) a cumplirse en el 2030, las metas son: eliminar la pobreza, mediante la elaboración de emprendimientos y productos turísticos gestados por la misma comunidad, que, a la larga, podrá desarrollar económicamente etas comunidades. La segunda meta es eliminar el hambre, pues el propio desarrollo comunitario incrementará el poder adquisitivo de éstas, accediendo a una alimentación saludable, reduciendo los niveles de desnutrición en la comunidad.

El turismo es una actividad desarrolladora que favorece a mejorar los sistemas educativos y a una mejor igualdad de género, pues el desarrollo de esta actividad, es un sector incluyente, y toda la unidad trabaja en conjunto que mejora la calidad de vida, y así; incrementar los niveles de empleo decente y el desarrollo de la economía local (Velasco, 2016).

También se puede agregar la importancia del acatamiento de los objetivos del Plan Nacional de Desarrollo 2017 - 2021 según Senplades (2017): Objetivo uno se basa en garantizar una vida digna con iguales oportunidades, mejorando la calidad de vida de la población de forma inclusiva, donde el turismo promueva la inclusión económica y social del territorio. Objetivo cinco, impulsar la productividad y competitividad para el crecimiento económico o sostenible de manera redistributiva y solidaria, basada en la generación del trabajo mediante el mejoramiento de las capacidades locales y generación de emprendimientos turísticos como artesanías locales, además creando ventaja competitiva con otros destinos para aprovechar al turismo como medio para el crecimiento económico. Objetivo nueve garantizar la soberanía y la paz, y posicionar estratégicamente el país en la región y el mundo; el turismo fomenta la creación del respeto, tolerancia promoviendo la construcción de espacios de encuentro común y fortaleciendo la identidad nacional y de esta forma lograr un crecimiento sostenido de la actividad (Senplades, 2017).

El turismo en la República de Ecuador tiene dificultades en los procesos de dirección, organización y optimización en los diferentes niveles gubernamentales, por tanto, se debe tener una forma que facilite intervenir a partir de los procesos políticos superiores, para de esa forma, tener una correcta intervención de los procesos turísticos locales e integrar a todos los entes de manera unida, manteniendo una correcta articulación de todos los procesos que anteriormente se explicaron.

El Gobierno Autónomo Descentralizado Municipal del Cantón Guamote dentro de la unidad de turismo actualmente carecen de acciones para gestionar correctamente el turismo y de esta forma dar cumplimiento a las competencias transferidas desde el gobierno central que son mandatos obligatorios, donde se especifica el fortalecer el desarrollo turístico del cantón.

Por tanto, el objetivo de este estudio fue determinar la influencia de la organización local turística municipal en el desarrollo turístico del cantón Guamote, provincia de Chimborazo. ofreciendo información fiable y actualizada para lograr una gestión 
adecuada del territorio, y que, de esta manera, se pueda forjar variados beneficios a las localidades, dentro de los objetivos y líneas que tiene el establecimiento estatal para obtener un correcto desarrollo turístico en la localidad.

El Problema Científico de nuestro estudio fue: ¿Cómo la organización local turística municipal incide en el desarrollo turístico del Cantón Guamote, Provincia de Chimborazo? Y la hipótesis planteada fue que la organización local municipal influye significativamente en el desarrollo turístico del cantón Guamote, provincia de Chimborazo.

\section{Metodología.}

Se realizó un estudio de corte cuantitativo pues se analizaron los datos de manera estadísticos y así evidenciar la confiabilidad de los instrumentos utilizados, como la tabulación de las encuestas aplicadas y comprobación de hipótesis. El diseño de estudio fue transversal porque se recolectó los datos en un solo momento y en un tiempo único, por medio de una entrevista al encargado de la unidad de turismo, y la aplicación de encuestas a los prestadores de servicio como a la población, tanto la entrevista como las encuestas son aplicadas una única vez en un fin de semana de alta afluencia turística. El estudio también fue de campo para de esta manera obtener información primaria mediante la aplicación de encuestas a prestadores de servicio y población, como también entrevista al director de la unidad de turismo del Gobierno Autónomo Descentralizado del Cantón Guamote, que constituyó el sector donde existe el problema.

\section{Unidad de análisis.}

Para la variable independiente - organización local turística: Lo conformaron los prestadores de servicio, quienes colaboraron para la obtención de datos; además, se tomó al director de la unidad de turismo para ser aplicada una entrevista con el objetivo de fortalecer los criterios de la gestión y desarrollo turístico del territorio.

En el caso de la variable dependiente - desarrollo turístico: se consideró a la población económicamente activa quienes aportaron con datos necesarios para el presente estudio.

\section{Población de estudio.}

Población I - variable independiente: Corresponden a los prestadores de servicio, según la Unidad de turismo Guamote (2019), son 83 prestadores, para conocer sobre la gestión.

Población II - variable dependiente: Para la segunda población el universo lo constituyen la población económicamente de Guamote datos que se encuentran en Gobierno Autónomo Descentralizado del Cantón Guamote, 2014-2019 con un total de 17.793 personas.

Tamaño de la muestra 


\section{Muestra I}

Para el cálculo de la muestra que corresponde a los prestadores de servicio con un total de 83 personas, quienes permitieron recabar información adecuada sobre la gestión actual de la unidad de turismo. La fórmula que se utilizó son la sugerida por Hernández Sampieri, Fernández Collado, \& Baptista Lucio (2010), para población finita.

\section{Fórmula:}

$\mathrm{n}=\left(\mathrm{Z}^{\wedge} 2 \cdot \mathrm{p} \cdot \mathrm{q} \cdot \mathrm{N}\right) /\left(\mathrm{N} \cdot \mathrm{E}^{\wedge} 2+\mathrm{Z}^{\wedge} 2 \cdot \mathrm{p} \cdot \mathrm{q}\right)$

Aplicando la fórmula se determinó que para una población de 83 personas el número de encuestas aplicadas son de 68 encuestas.

\section{Muestra II}

Para el cálculo del tamaño de la muestra se considera un total 17.793, lo cual lo conformaron la población económicamente activa y mediante ello se va a poder conocer el desarrollo actual del turismo dentro del sector, en donde se utilizó la fórmula para la población finita y conocida de (Canavos, 1992).

Aplicando la misma fórmula anterior se determinó que para una población de 17793 personas el número de encuestas aplicadas son de 376.

\section{Técnicas e instrumentos de investigación}

\section{Encuesta.}

Las respuestas son formuladas por escrito y no se requiere de la presencia del investigador. Fueron aplicadas 2 encuestas: una a los prestadores de servicio, quienes contribuyeron para conocer la gestión actual que desempeña la unidad de turismo y detectar las falencias de la misma. Compuesta por 8 preguntas (ejemplos: ¿Conoce usted de las políticas turísticas de actuación local por parte del Gobierno Autónomo Descentralizado Municipal del Cantón Guamote? ¿Cuentan con una estructura organizacional en tema turístico dentro del Cantón?).

Y otra encuesta a la población económicamente activa del cantón Guamote, con el objetivo de conocer el punto de vista sobre el desarrollo turístico dentro del territorio de estudio, compuesta por 5 preguntas (ejemplos: ¿Cómo califica usted el desarrollo turístico en el Cantón Guamote? ¿Cómo calificaría usted las actividades que realiza el GAD de Guamote en beneficio del turismo, para el mejoramiento de la calidad del servicio?).

Los instrumentos constaron de preguntas abiertas y cerradas, como también en base a la escala de Likert, elaborado para los prestadores de servicio y la población del cantón.

\section{Validez de los instrumentos.}


Para evaluar la validez del instrumento se realizó un juicio de expertos. Esta validación arrojó los siguientes resultados: los instrumentos tienen un diseño adecuado, se encuentra en relación a la investigación de acuerdo a las variables de estudio brindando información óptima para el logro de los objetivos, teniendo una relación coherente con las variables e indicadores, concluyendo que el instrumento aporta a un análisis adecuado con alternativas entendibles para la población de estudio y contribuye al logro de los objetivos.

\section{Confiabilidad de los instrumentos.}

Según los resultados del Alfa de Cronbach, la variable organización es 0.854 y desarrollo turístico corresponde a 0,835 , pudiendo determinar que la fiabilidad de los instrumentos es confiable porque se encuentra en el rango de aceptación.

Ética en la investigación

La planificación de estas investigaciones se realizó teniendo en cuenta los lineamientos de la Declaración de Helsinki de 1973, revisada en 1986 y enmendada en octubre de 2013, y también se rigió por las normas estándar vigentes en la República del Ecuador para la realización de investigaciones científicas.

\section{Resultados.}

En este punto se realizó el análisis de los resultados de las encuestas aplicadas a la unidad de turismo del Gobierno Autónomo Descentralizado del Cantón Guamote, prestadores de servicios y a la población, con el fin de conocer las variables de estudio, el análisis fue realizado en software informático IBM SPSS Statistics Versión 25. Los resultados de la tabulación de cada una de las preguntas de las encuestas de organización y desarrollo turístico, contienen una tabla con frecuencia y porcentaje, al igual que un gráfico en barras con los porcentajes correspondiente.

\section{Resultados de la aplicación de la encuesta aplicada a los prestadores de servicio}

Pregunta 1. ¿El Gobierno Autónomo Descentralizado Municipal del Cantón Guamote cuenta con políticas turísticas de actuación?

Tabla 1. Política Turísticas del GAD

\begin{tabular}{cccccc}
\hline & & Frecuencia & Porcentaje & $\begin{array}{c}\text { Porcentaje } \\
\text { válido }\end{array}$ & $\begin{array}{c}\text { Porcentaje } \\
\text { acumulado }\end{array}$ \\
\hline \multirow{3}{*}{ Válido } & Si & 2 & 2,9 & 2,9 & 2,9 \\
& No & 66 & 97,1 & 97,1 & 100 \\
& Total & 68 & 100 & 100 & \\
\hline
\end{tabular}

Fuente: Elaboración propia. 
De acuerdo a los resultados obtenido se puede ver el 97\% de las personas desconocen las políticas turísticas, y el $3 \%$ manifiestan que conoce de políticas que incluyen la conservación de los recursos naturales, se concluye que dentro del Plan de Desarrollo y Ordenamiento Territorial no cuenta con políticas turísticas para un adecuado manejo y orientación sobre la actividad. Es necesario que la Unidad de Turismo establezca la política de actuación para lograr una orientación y cumplimiento de las competencias a cargo.

Pregunta 2. ¿Existe una estructura organizacional turística dentro del Cantón?

Tabla 2. Organización turística

\begin{tabular}{cccccc}
\hline & Frecuencia & Porcentaje & $\begin{array}{c}\text { Porcentaje } \\
\text { válido }\end{array}$ & $\begin{array}{c}\text { Porcentaje } \\
\text { acumulado }\end{array}$ \\
\hline \multirow{3}{*}{ Válido } & Si & 5 & 7,4 & 7,4 & 7,4 \\
& No & 63 & 92,6 & 92,6 & 100 \\
& Total & 68 & 100 & 100 & \\
\hline
\end{tabular}

Fuente: Elaboración propia.

El mayor porcentaje con un 93\%, manifiesta que la municipalidad no cuenta con una estructura organizacional mientras, que el $7 \%$ manifiestan que si de acuerdo. La estructura organizacional dentro de un municipio, es necesario porque permite conocer las directrices y las necesidades prioritarias del destino, por lo que es necesario que se implemente una estructura óptima de acuerdo a las áreas críticas de actuación que puede tener el cantón en tema turístico.

Pregunta 3. ¿La municipalidad tiene un plan de desarrollo turístico?

Tabla 3. Plan turístico

\begin{tabular}{cccccc}
\hline & & Frecuencia & Porcentaje & Porcentaje válido & Porcentaje acumulado \\
\hline Válido & No & 68 & 100 & 100 & 100 \\
\hline
\end{tabular}

Fuente: Elaboración propia.

El $100 \%$ de los encuestados manifiestan que no poseen con una planificación, concluyendo que dentro del cantón no existen políticas públicas para impulsar el turismo, por ende, no existe un plan general de actuación con un alcance a corto, mediano y largo tiempo, estableciendo las bases estratégicas para el desarrollo turístico del sector.

Pregunta 4. ¿Cómo califica la planificación del turismo, lo realizan en conjunto con los actores claves? 
Tabla 4. Planificación turística participativa

\begin{tabular}{cccccc}
\hline & & Frecuencia & Porcentaje & Porcentaje válido & Porcentaje acumulado \\
\hline \multirow{4}{*}{ Válido } & Buena & 1 & 1,5 & 1,5 & 1,5 \\
& Regular & 14 & 20,6 & 20,6 & 22,1 \\
& Mala & 53 & 77,9 & 77,9 & 100 \\
& Total & 68 & 100 & 100 & \\
\hline
\end{tabular}

Fuente: Elaboración propia.

Se puede observar que la planificación con los actores claves en el sector es mala con el $78 \%$, seguido de regular con $21 \%$, y el $1 \%$ es buena. La gestión municipal de Guamote tiene un modelo fragmentado de los actores locales, por lo tanto, es esencial que la gestión turista contribuya a mejorar la articulación entre las distintas entidades basándose en las competencias que tiene cada sector. La gestión turística del municipio solicita la conformación de una estructura de cooperación entre el sector público y el sector privado: ambos sectores deben impulsar decisiones encaminadas a un propósito fundamental, que es satisfacer a los turistas.

Pregunta 5. ¿Cómo es la asignación presupuestaria en turismo?

Tabla 5. Asignación presupuestaria

\begin{tabular}{cccccc}
\hline & & Frecuencia & Porcentaje & Porcentaje válido & Porcentaje acumulado \\
\hline \multirow{3}{*}{ Válido } & Regular & 13 & 19,1 & 19,1 & 19,1 \\
& Mala & 55 & 80,9 & 80,9 & 100 \\
& Total & 68 & 100 & 100 & \\
\hline
\end{tabular}

Fuente: Elaboración propia.

La mayor parte considera que la asignación presupuestaria en turismo es mala con un $81 \%$ y el $19 \%$ manifiesta que es regular, concluyendo que dentro del municipio no existe presupuesto adecuado para temas turísticos, porque al ser una unidad que está dentro de la dirección de desarrollo local, el presupuesto es mínimo para el impulso de la actividad turística.

Pregunta 6. ¿Cree usted que el personal en territorio conoce las competencias del GAD y cómo influyen en las organizaciones turísticas?

Tabla 6. Conocimiento las competencias

\begin{tabular}{llcccc}
\hline Frecuencia & Porcentaje & $\begin{array}{c}\text { Porcentaje } \\
\text { válido }\end{array}$ & $\begin{array}{c}\text { Porcentaje } \\
\text { acumulado }\end{array}$ \\
\hline Válido & Si & 11 & 16,2 & 16,2 & 16,2 \\
& No & 57 & 83,8 & 83,8 & 100,0 \\
& Total & 68 & 100,0 & 100,0 & \\
\hline
\end{tabular}

Fuente: Elaboración propia. 
Según la tabla 6, la mayor parte de la población con un $84 \%$ desconoce las competencias que tiene el municipio en tema turístico, mientras que el 16\% manifiesta que sí sabe las competencias. Dentro del cantón los prestadores de servicio que conocen las competencias de la unidad de turismo manifestaron que ninguna se aplica dentro del cantón, que ellos se sienten desorientados para poder mejorar el servicio.

Pregunta 7. ¿Tiene un sistema de información para controlar el número de turistas?

Tabla 7. Sistema informático para el control de turistas

\begin{tabular}{cccccc}
\hline & & Frecuencia & Porcentaje & Porcentaje válido & Porcentaje acumulado \\
\hline \multirow{3}{*}{ Válido } & Si & 5 & 7,4 & 7,4 & 7,4 \\
& No & 63 & 92,6 & 92,6 & 100,0 \\
& Total & 68 & 100,0 & 100,0 & \\
\hline
\end{tabular}

Fuente: Elaboración propia.

La mayor parte de los prestadores de servicio no cuentan con un sistema de información para registrar el número de turistas que llegan en un 93\%, mientras que el $8 \%$ tiene un sistema informático de registro, dando como resultado que en el cantón no posee datos, desde el municipio solo se registra el número de personas que piden información turística en un registro voluntario para la Mesa de Turismo de la municipalidad de Guamote, y los prestadores de servicio solo dos tiene un registro que son el Hotel Chuzalonga y la Fundación Inti Sisa, centros turística amplios y equipados en el sector.

Pregunta 8. ¿Cree usted que es necesario contar estrategias de gestión y planificación para mejorar el desarrollo turístico en el Cantón?

Tabla 8. Estrategias de gestión y planificación

\begin{tabular}{cccccc}
\hline & & Frecuencia & Porcentaje & Porcentaje válido & Porcentaje acumulado \\
\hline \multirow{4}{*}{ Válido } & Si & 57 & 83,8 & 83,8 & 83,8 \\
& No & 11 & 16,2 & 16,2 & 100 \\
& Total & 68 & 100 & 100 & \\
\hline
\end{tabular}

Fuente: Elaboración propia.

Los resultados obtenidos muestran que el $84 \%$ de los prestadores de servicios creen que es necesario tener estrategias de gestión y planificación para poder mejorar el turismo dentro del sector en comparación al $16 \%$ que no ve necesario.

\section{Resultados de la encuesta aplicada a la población perteneciente al Cantón Guamote.}

Pregunta 1. ¿Cómo califica usted el desarrollo turístico (considerando que este aporta al mejoramiento socio - económico del sector) en el Cantón Guamote? 
Tabla 9. Desarrollo turístico socio - económico

\begin{tabular}{clcccc}
\hline & & Frecuencia & Porcentaje & Porcentaje válido & Porcentaje acumulado \\
\hline \multirow{3}{*}{ Válido } & Buena & 31 & 8,2 & 8,2 & 8,2 \\
& Regular & 131 & 34,8 & 34,8 & 43,1 \\
& Mala & 213 & 56,6 & 56,6 & 99,7 \\
& Total & 376 & 100 & 100 & \\
\hline
\end{tabular}

Fuente: Elaboración propia.

Las opciones vertidas, muestran que el desarrollo turístico del cantón Guamote es mala con un $57 \%$, seguida por regular en un $35 \%$, se concluye que la mayor parte de la población no toman al turismo como algo relevante, o como un medio de mejoramiento económico del sector, es decir que esta población tiene la precepción que actualmente el turismo se encuentra mal manejado y sin resultados óptimos.

Pregunta 2. ¿Cómo calificaría usted las actividades que realiza el GAD de Guamote en beneficio del turismo, para el mejoramiento de la calidad del servicio?

Tabla 10. Actividades del GAD en beneficio del turismo

\begin{tabular}{llcccc}
\hline & & Frecuencia & Porcentaje & Porcentaje válido & Porcentaje acumulado \\
\hline \multirow{3}{*}{ Válido } & Regular & 98 & 26,1 & 26,1 & 26,1 \\
& Mala & 278 & 73,9 & 73,9 & 100 \\
& Total & 376 & 100 & 100 & \\
\hline
\end{tabular}

Fuente: Elaboración propia.

De acuerdo a las encuestas el $74 \%$ de la población de Guamote, menciona que el municipio, no realiza ninguna actividad en beneficio del turismo para el mejoramiento de la calidad de los servicios, por lo que necesario la ejecución de inversiones en infraestructura y facilidades, generando capacidades locales e innovación, estableciendo una oferta estructurada de bienes y servicios turísticos afines a los requerimientos de los turistas y aprovechando las ventajas territoriales.

Pregunta 3. ¿Cómo calificaría usted las instalaciones de los restaurantes, hoteles, centros turísticos, dentro del Cantón?

Tabla 11. Instalaciones de los restaurantes, hoteles y centros turísticos

\begin{tabular}{llcccc}
\hline & & Frecuencia & Porcentaje & Porcentaje válido & Porcentaje acumulado \\
\hline \multirow{4}{*}{ Válido } & Buena & 40 & 10,6 & 10,6 & 10,6 \\
& Regular & 101 & 26,9 & 26,9 & 37,5 \\
& Mala & 235 & 62,5 & 62,5 & 100 \\
& Total & 376 & 100 & 100 & \\
\hline
\end{tabular}

Fuente: Elaboración propia. 
Los resultados obtenidos muestran que las instalaciones de los restaurantes, hoteles y centros turísticos dentro del cantón son malas con un $62 \%$, regular con un $26 \%$ y con el $11 \%$ que son buenos. Dentro del sector existe deficiencias en el servicio, las medidas de aseo se deberían mejorar al igual que las instalaciones para que el turista se siente satisfecho y pueda consumir dentro del cantón lo que es alimentación, recreación generando de esta forma fuentes de ingreso.

Pregunta 4. ¿Qué opina usted en relación al turista que visita el cantón, se siente satisfechos con los servicios que dan los prestadores de servicio?

Tabla 12. Satisfacción de los turistas

\begin{tabular}{clcccc}
\hline & & Frecuencia & Porcentaje & Porcentaje válido & Porcentaje acumulado \\
\hline \multirow{2}{*}{ Válido } & Si & 142 & 37,8 & 37,8 & 37,8 \\
& No & 230 & 61,2 & 61,2 & 98,9 \\
& No sabe & 4 & 1,1 & 1,1 & 100 \\
& Total & 376 & 100 & 100 & \\
\hline
\end{tabular}

Fuente: Elaboración propia.

De acuerdo a las encuestas aplicadas el $62 \%$ de la población opinan que los turísticas no se sienten satisfechos con los servicios que dan los prestadores, que todavía es necesario trabajar en mejoramiento a la atención del cliente, y optar por lugares de acuerdo al perfil del turista y por temporalidad de visita.

Pregunta 5. ¿Existe capacitación constante a los prestadores de servicio?

Tabla 13. Capacitación a los prestadores de servicio

\begin{tabular}{llcccc}
\hline & & Frecuencia & Porcentaje & Porcentaje válido & Porcentaje acumulado \\
\hline & Si & 84 & 22,3 & 22,3 & 22,3 \\
Válido & No & 292 & 77,7 & 77,7 & 100 \\
& Total & 376 & 100 & 100 & \\
\hline
\end{tabular}

Fuente: Elaboración propia.

Dentro del cantón Guamote, aplicando las encuestas, el 78\% manifestaron que no existen capacitaciones para los prestadores de servicio, mientras que el $22 \%$ señalan que dentro del municipio existe capacitaciones en temas agrícolas y ganaderos.

Resultados de la prueba de hipótesis

Para verificar la hipótesis se escogió la herramienta de = Chi - cuadrado.

$$
\mathrm{X}^{\wedge} 2=\sum(\llbracket(\text { fo-fe }) \rrbracket \wedge 2 / \mathrm{fe})
$$


Para la comprobación de la hipótesis se realizó en el software estadístico IBM SPSS Statistic V.25, considerando cada una de las variables y dimensiones especificadas para la investigación.

El p_valor $=0,011<0,05$ alfa; esto quiere decir que de acuerdo a la regla de aceptación establecida se rechaza la hipótesis nula $\left(\mathrm{H}_{-} 0\right)$ y se acepta la hipótesis alterna $\left(\mathrm{H} \_1\right)$. Por lo tanto, se concluye que: La organización local municipal influye significativamente en el desarrollo turístico del cantón Guamote, provincia de Chimborazo

Tabla 14. Chi - Cuadrado Hipótesis

\begin{tabular}{lccc}
\hline & Valor & gl & $\begin{array}{c}\text { Significación asintótica } \\
\text { (bilateral) }\end{array}$ \\
\hline Chi-cuadrado de Pearson & $13,151^{\mathrm{a}}$ & 4 & 0,011 \\
Razón de verosimilitud & 5,786 & 4 & 0,216 \\
Asociación lineal por lineal & 1,077 & 1 & 0,299 \\
N de casos válidos & 68 & & \\
\hline
\end{tabular}

Fuente: Elaboración propia.

\section{Discusión.}

El principal objetivo de este estudio fue determinar la influencia de la organización local turística municipal en el desarrollo turístico del cantón Guamote, provincia de Chimborazo. Y así, en la Unidad de Turismo contribuir a la mejoría del progreso turístico en la localidad, desde un análisis situacional, descubriendo dificultades y teniendo en cuenta a la institución como una entidad pública, siempre con la idea de mejorar sus servicios y de esta manera fortalecer el desarrollo turístico del Cantón.

Luego de analizar varios estudios nacionales e internacionales se pudo hallar uno realizado en Europa que trata de la planificación y gestión dl turismo sostenible, mediante la intervención en la costa interior de Extremadura: el embalse de la Serena. Los resultados mostraron que este destino turístico pudo ser popularizado desde el estudio de la oferta y demanda, mostrando sus debilidades y fortalezas y de esta manera planificar de manera correcta y así dirigir los procesos territoriales de manera adecuada (Andrade, 2008, p. 48).

Otro ejemplo fue el publicado en la revista cuaderno de turismo donde se llama a nuevas formas para desarrollar nuevos destinos turísticos mediante: marcos conceptuales y funcionales de dirección en este sentido. Según los autores el turismo ha crecido favorablemente en la actualidad, y esto ha hecho que haya un cambio de estrategias que conlleva a una nueva forma de atención q la organización turística de manera integral, utilizando correctos métodos organizativos para un verdadero turismo sostenible y competidor (Barrado \& Reyes, 2015, p. 27). 
Santana-Turégan (2003, p.19) realizaron un estudio sobre los procesos de planificación y gestión dentro del campo del turismo sostenible. Los autores proponen la elaboración de un procedimiento de indicadores desde el desarrollo sostenible, y así proponer nuevas maneras de hacer dentro del turismo territorial y el medio ambiente. Esta metodología, que se aplicó en la capital de España, posee índices y equipos informativos en las ciencias geográficas con relación al turismo, llevando correctamente el equilibrio y la sostenible del desarrollo turístico. Estos elementos no tienen la suficiente intervención desde la ciencia actual, marcando entonces como una contribución para los procesos de dirección territorial turística.

En nuestro continente americano se realizó un estudio sobre turismo y desarrollo en México, donde se expone el horizonte del turismo, como una importante posibilidad de incremento internacional, aquí se centra, fundamentalmente en los procesos de oferta y demanda, y los impactos económicos del turismo a nivel internacional en instituciones públicas, y así obtener mejores resultados a nivel territorial (Altés, 2008, p. 39).

Adentrándonos en el Ecuador hay algunas investigaciones similares, una ejecutada por la Universidad Regional Autónoma de los Andes, en la que se aplica un guía de gestión turística local integrada y participativa, promoviendo el desarrollo local como instrumento de mejoría de la calidad de vida en la población del territorio, partiendo de la oferta y demanda del sector, y fortaleciendo las potencialidades para satisfacer los diferentes mercados turísticos (Salas, Font, \& Suáres Mella, 2016, p. 6).

Otro estudio en el Ecuador trata sobre el modelo de gestión para fomentar el desarrollo turístico de las comunidades de la provincia de Manabí, y parte de un análisis de la situación de este territorio y la gestión turística y de ahí proponer un plan estratégico. Aquí se identifican los principales representantes, los procesos de inversión y los proyectos para el gobierno local y asñi trabajar en el desarrollo de un turismo comunitario sostenible (Reinoso, 2017, p. 35).

Otro estudio realizado por Arias Guadalupe (2015, p. 115), en la parroquia Santiago de Quito, planea lineamientos estratégicos para una adecuada gestión, aportando un grupo de acciones comunitarias, diseño de productos, comercialización y la intervención de importantes elementos de los sectores públicos y privados y así lograr un mejor proceso de dirección en el sector turístico.

Después de lo anteriormente planteado, se puede observar que en el cantón Guamote no hay establecimiento registrados en un catastro y reconocidos por el ministerio de turismo, aunque es esencial tener en cuenta que el sector turístico incluye transporte, alojamiento, alimentación, recreación, guianza y agencias de viajes, todos estos elementos son esenciales dentro de un correcto desarrollo turístico local. Hay un crecimiento desorganizado del sector, y la gran parte de los servidores en estos prestadores en este campo ejercen la actividad de una forma incorrecta, además los inversionistas en este sector desconocen la actual problemática, y uno de los principales problemas de desarrollo en el sector es la falta de una ordenanza turística dentro del cantón. 
En la Unidad de Turismo Local los servidores públicos tienen abierta sus puertas desde el jueves al domingo, y solo 2 atienden los días normales, específicamente el día jueves hay una feria en la cabecera parroquial por lo que aumenta 15 salones de comida en la cabecera cantonal, en Cebadas hay unos 10 puestos más que atienden de manera informal, y 14 puestos de comida en Palmira que atienden los días jueves y domingo. En total dentro del cantón se tiene registrado que existe 71 puestos de alimentación y bebidas.

Los turistas nacionales que vienen al cantón son principalmente de las provincias de Guayaquil, Pichincha, Tungurahua, Chimborazo. La mayoría están en los grupos etarios de entre los 30 - 55 años, son casados, de educación superior, la mayoría viene sólo a vacacionar, o a visitar a familiares, amigos. Y también por las fiestas del carnaval, el promedio de gastos diarios es de unos 25 dólares (Movilización, alimentación), están interesados en conocer la feria indígena, artesanías, recorrido en tren, y su tiempo de estadía es de 1 a 2 días; tienen algunas dificultades con poder llegar correctamente al cantón, el déficit de información turística, aunque adoran la calidad del medio ambiente en éste, específicamente en el complejo lacustre Hatillo.

Según un estudio realizado por Herredia (2010, p. 138) los principales turistas del exterior que visitan el cantón Guamote son de Francia, Suiza, Australia, Alemania, Bélgica, Estados Unidos, Holanda de género masculino en su mayoría, comprendidos en una edad de 46 - 55 años, seguidos por 31 - 45 años de edad, que viajen en los meses de enero mayo principalmente los turistas franceses, suizos, holandeses y estadounidenses, de junio - septiembre los turistas australianos, alemanes y holandeses, siendo los meses de temporalidad baja entre octubre y diciembre, y temporalidad alta de enero a junio. Ellos al llegar al cantón chocan con la dificultad de la falta de información turística y el desconocimiento del destino interesante del tren, y el mercado indígena de los días jueves: también el deficiente servicio gastronómico y la movilidad dentro de éste. El gasto promedio de ellos es de 50 - 100 dólares y su estancia es de 1 - 3 días.

\section{Conclusiones:}

- El presente estudio permitió conocer sobre la gestión y la influencia en el desarrollo turístico del Gobierno Autónomo Descentralizado del Cantón Guamote. Con la comprobación de la hipótesis se determinó que la gestión influye significativamente en un 0.008 , es decir que se ha identificado las debilidades existentes dentro del municipio y la relación con los servidores del sector, conociendo que dentro del cantón Guamote es necesario contar con una correcta gestión turística integrada y participativa que conlleve al desarrollo local.

- Los prestadores de servicio, en su gran mayoría no conocen las políticas turísticas. El Plan de Desarrollo y Ordenamiento Territorial no cuenta con políticas turísticas para una correcta dirección de esta importante actividad. Es indispensable que la Unidad de Turismo instaure políticas correctas para de esta manera poder cumplir mejor sus objetivos planteados, según sus competencias. El municipio no tiene 
una estructura organizacional y ésta, es indispensable pues permite conocer las directrices y las necesidades prioritarias del destino, por lo que es necesario que se implemente una estructura óptima de acuerdo a las áreas críticas de actuación que puede tener el cantón en tema turístico. Y no poseen una planificación, concluyendo que dentro del cantón no existen políticas públicas para impulsar el turismo, por ende, no existe un plan general de actuación con un alcance a corto, mediano y largo tiempo, estableciendo las bases estratégicas para el desarrollo turístico del sector.

- Al analizar la influencia de la organización turística municipal en el desarrollo turístico del cantón Guamote se pudo observar una significancia del 0,011; es decir que, si no cuenta con una estructura organizativa que permita proponer estrategias adecuadas para el desarrollo turístico de la zona, este va a presentar deficiencias en el cumplimiento de las competencias específicas que tiene la Unidad de Turismo.

\section{Referencias bibliográficas:}

Altés, C. (2008). Turismo y Desarrollo en México. (B. I. Desarrollo, Ed.) 38-41. Recuperado de https://publications.iadb.org/bitstream/handle/11319/3962/Turismo\%20y\%20des arrollo\%20en\%20M\%C3\%A9xico.pdf?sequence=1

Andrades, L. (2008). Gestión y Planificación turística sostenible. Aplicación a un destino de costa interior de Extremadura: el embalse de La Serena. Revista de Estudios Empresariales, Segunda época(2), 24-47. Recuperado de ttps://www.researchgate.net/publication/28243452_Planificacion_turistica_y_so stenible_Aplicacion_a_un_destino_de_costa_interior_de_Extremadura_el_emba lse_de_La_Serena

Arias Guadalupe, L. d. (2015). Modelo de gestión administrativa turistica en la parroquia Santiago de Quito, cantón Colta, provincia de Chimborazo. Universidad Nacional de Chimborazo, Tesis previo a la obtención del titulo de Master en Marketing Turistico (pág. 22). Riobamba.

Barrado Timón, D., \& Reyes Avila , B. (2015). Nuevas tendencias en el desarrollo de destinos turísticos: marcos conceptuales y operativos para su planificación y gestión. Cuadernos de turismo (25), 15.

Gobierno Autónomo Descentralizado del Cantón Guamote. (2014-2019). PD y OT. Recuperado de https://www.municipiodeguamote.gob.ec/concejo-cantonal/plande-desarrollo/1595-pd-y-ot-guamote/file

Heredia Estefanía, (2010). Guamote intercultural y ancestral. Universidad Politécnica Salesiana.

Hernández Sampieri, R., Fernández Collado, C., \& Baptista Lucio, P. (2010). Metodología de la investigación (Quinta ed.). (J. M. Chacón, Ed.) México D.F: McGraw - Hill. 
Ministerio de turismo. (2018). Ministerio de turismo del Ecuador. Recuperado de Visitas: https://www.turismo.gob.ec/ecuador-llega-por-primera-vez-a-2-millones-devisitas-extranjeras-a-octubre-de-este-ano/

Organización de las Naciones Unidas. (2016). Objetivos de Desarrollo Sostenible. Recuperado de https://www.cepal.org/es/temas/agenda-2030-desarrollosostenible/objetivos-desarrollo-sostenible-ods

Reinoso, N. G. (2017). Modelo de gestión para fomentar el desarrollo turístico de las comunidades manabita del ecuador. Cultura, 35.

Santana Rosero, M. A. (2017). El Control. Recuperado de http://exa.unne.edu.ar/informatica/sistemas.adm1/material/tema-7.pdf

Santana Turégan, M. Á. (2003). Formas de Desarrollo Turístico, Redes y situación de empleo. El caso de Maspalmas (Gran Canaria). (G. canaria, Ed.) Recuperado de www.tesisencarca.net/TESIS_UAD/AVAILABLE/TDX.PDF.

Salas Álvarez, W., Font Aranda, M., \& Suáres Mella, R. (2016). Consideraciones para un modelo de gestión turistica local integrada y participativa. (Uniandes, Ed.) Impacto de las investigaciones Universitarias, 6.

Senplades, S. N. (2017). Plan Nacional de Desarrollo 2017-2021 Toda una Vida. Plan Nacional de Desarrollo 2017-2021 Toda una Vida. https://www.planificacion.gob.ec/wpcontent/uploads/downloads/2017/10/PNBV-26-OCT-

FINAL_0K.compressed1.pdf

Unidad de turismo Guamote. (2019). Catastro turístico. Guamote, Chimborazo.

Uribe, A. (2016). La gestión en las organizaciones. EUMED. Recuperado de http://www.eumed.net/librosgratis/2010c/758/La\%20Gestion\%20en\%20las\%20 organizaciones.htm

Velasco, M. (2016). Entre el poder y la racionalidad: gobierno del turismo, polica turística, planificación turistica y gestión pública del turismo. Pasos Revista de Turismo y Patrimonio Cultural, 577-594.

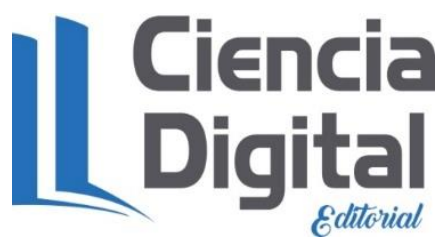




\section{PARA CITAR EL ARTÍCULO INDEXADO.}

Proaño Lucero, G. E. (2020). Influencia organizacional en el desarrollo turístico del cantón Guamote, Ecuador. Explorador Digital, 4(3), 92-109. https://doi.org/10.33262/exploradordigital.v4i3.1291

\section{Ciencia \\ Ligital}

El artículo que se publica es de exclusiva responsabilidad de los autores y no necesariamente reflejan el pensamiento de la Revista Ciencia Digital.

El artículo queda en propiedad de la revista y, por tanto, su publicación parcial y/o total en otro medio tiene que ser autorizado por el director de la Revista Ciencia Digital.
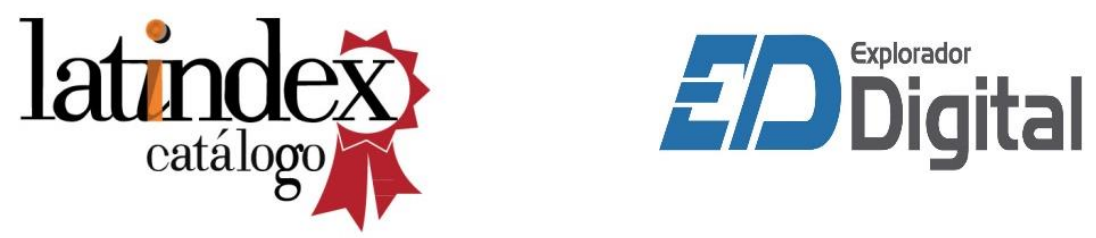